\title{
Article \\ Disposition Decision Support by Laboratory Based Outcome Prediction
}

\author{
Oliver S. Mueller ${ }^{1}$, Katharina M. Rentsch ${ }^{2}$, Christian H. Nickel ${ }^{1}$ and Roland Bingisser ${ }^{1, *}$ \\ 1 Emergency Department, University Hospital Basel, 4031 Basel, Switzerland; \\ oliversimon.mueller@usb.ch (O.S.M.); christian.nickel@usb.ch (C.H.N.) \\ 2 Laboratory Medicine, University Hospital Basel, 4031 Basel, Switzerland; katharina.rentsch@usb.ch \\ * Correspondence: roland.bingisser@usb.ch; Tel.: +41-61-265-58-30; Fax: +41-61-265-58-31
}

Citation: Mueller, O.S.; Rentsch, K.M.; Nickel, C.H.; Bingisser, R. Disposition Decision Support by Laboratory Based Outcome Prediction. J. Clin. Med. 2021, 10, 939 https://doi.org/10.3390/jcm10050939

Academic Editor: John G. Kellett

Received: 24 January 2021

Accepted: 23 February 2021

Published: 1 March 2021

Publisher's Note: MDPI stays neutral with regard to jurisdictional claims in published maps and institutional affiliations.

Copyright: (c) 2021 by the authors. Licensee MDPI, Basel, Switzerland. This article is an open access article distributed under the terms and conditions of the Creative Commons Attribution (CC BY) license (https:// creativecommons.org/licenses/by/ $4.0 /)$.

\begin{abstract}
Disposition is one of the main tasks in the emergency department. However, there is a lack of objective and reliable disposition criteria, and diagnosis-based risk prediction is not feasible at early time points. The aim was to derive a risk score (TRIAL) based on routinely collected baseline (TRIage level and Age) and Laboratory data-supporting disposition decisions by risk stratification based on mortality. We prospectively included consecutive patients presenting to the emergency department over 18 weeks. Data sets of routinely collected baseline (triage level and age) and laboratory data were used for multivariable logistic regression to develop the TRIAL risk score predicting mortality. Routine laboratory variables and disposition cut-offs were chosen beforehand by expert consensus. Risk stratification was based on low risk $(<1 \%)$, intermediate risk $(1-10 \%)$, and high risk $(>10 \%)$ of in-hospital mortality. In total, 8687 data sets were analyzed. Variables identified to develop the TRIAL risk score were triage level (Emergency Severity Index), age, lactate dehydrogenase, creatinine, albumin, bilirubin, and leukocyte count. The area under the ROC curve for in-hospital mortality was 0.93 . Stratification according to the TRIAL score showed that $67.5 \%$ of all patients were in the low-risk category. Mortality was $0.1 \%$ in low-risk, $3.5 \%$ in intermediate-risk, and $26.2 \%$ in high-risk patients. The TRIAL risk score based on routinely available baseline and laboratory data provides prognostic information for disposition decisions. TRIAL could be used to minimize admission in low-risk and to maximize observation in high-risk patients.
\end{abstract}

Keywords: decision support; laboratory; outcome prediction; emergency medicine; triage; disposition; mortality; emergency severity index

\section{Introduction}

The three major tasks of emergency medicine are triage, work-up, and disposition [1]. If disposition (e.g., discharge, admission, or intensive care) is not given by logistic factors, such as the need for intervention, it is based on outcome prediction, as preventing admission of low-risk patients has become similarly important to preventing discharge of patients at risk of early deterioration or death.

As the economic pressure is rising and unexpected death after discharge is infrequent [2], unnecessary additional cost of hospitalization has moved to the center of attention in many health care systems. Resources used for hospitalized patients may be up to tenfold higher as compared to ambulatory care in comparable situations [1]. In spite of the existing research on outcome prediction (based on routine administrative data [3], vital signs [4-7], observation [8], machine learning [9], combinations of age, vital signs, and loss of independence [10], or admission laboratory data without [11] or with inclusion of patient age [12-14] or vital signs [15]), only a few studies have focused on the direct support of disposition decisions [8,16-18]. As all of these attempts have drawbacks and disease-specific tools rely on a sound diagnosis, a call for the development of a "Universal Safe to Discharge Score" was recently issued [19]. 
We have therefore aimed at improving disposition decisions using laboratory-based outcome prediction in combination with age and level of acuity, as these two factors contain the best baseline prognostic information [20-22]. Our primary objective was to develop a risk score based on the predictive performance of baseline and laboratory data in order to stratify patients into groups of low, intermediate, and high risk of short-term mortality.

\section{Materials and Methods}

\subsection{Study Design and Setting}

This is a secondary analysis of prospectively collected data of the EMERGE study, which serves as a quality-control study. The study protocol was approved by the local ethics board (EKNZ-236/13; www.eknz.ch, accessed date: 12 December 2019) and was conducted at the emergency department (ED) of the University Hospital Basel, Switzerland with a census of over 50,000 yearly presentations.

All patients presenting to the ED of the University Hospital Basel were eligible. Data were acquired consecutively from 21 October to 11 November 2013, 1 February to 23 February 2015, 30 January to 19 February 2017, and 18 March to 20 May 2019. By selecting different observation periods, we wanted to consider potential seasonal effects.

\subsection{Selection of Participants}

All consecutive patients presenting to the ED were screened. Patients who denied consent were not included. Pediatric, obstetric, and ophthalmology patients were treated at nearby facilities.

\subsection{Data Collection}

All patients presenting to the emergency department were registered by a member of the study team and an electronic health record (EHR) was opened. The study team consisted of trained medical students. Patients were screened $24 \mathrm{~h}$ a day, 7 days a week.

Information about demographics (age, gender), Emergency Severity Index (ESI) triage level, disposition (discharge, hospitalization, and intensive care unit admission), in-hospital mortality, and laboratory data were extracted from the EHR.

Only patients with full data sets were analyzed. We excluded patients with missing triage or laboratory data.

\subsubsection{Triage}

A triage nurse or emergency physician triaged all patients according to the German version of the ESI (version 4) [20].

ESI categorizes patients into five levels. High acuity patients are assigned to ESI level 1 (most urgent) or ESI level 2, while less acute patients are classified according to the expected number of resources required (none in ESI level 5 and more than one in ESI level 3) [23].

\subsubsection{Laboratory Data}

Laboratory data of the first examinations after presentation were used for all analyses. No additional tests were performed for study purposes only. If multiple blood samples were taken from the same patient, only results from the first set were analyzed. Cases were excluded if blood samples arrived at the laboratory later than $24 \mathrm{~h}$ after presentation, or if analyses were incomplete (for analysis: added to patient group "without laboratory data").

To ensure usefulness in everyday clinical practice, we restricted our investigation to routinely available laboratory parameters. The laboratory variables to be examined were determined beforehand by expert consensus. The decision was based on clinical relevance and previous publications [11-14,24]. Selected variables were sodium (mmol/L), potassium $(\mathrm{mmol} / \mathrm{L})$, urea $(\mathrm{mmol} / \mathrm{L})$, creatinine $(\mu \mathrm{mol} / \mathrm{L})$, bilirubin $(\mu \mathrm{mol} / \mathrm{L})$, aspartate transaminase $(\mathrm{U} / \mathrm{L})$, lactate dehydrogenase $(\mathrm{U} / \mathrm{L})$, albumin $(\mathrm{g} / \mathrm{L})$, C-reactive protein $(\mathrm{mg} / \mathrm{L})$, glucose $(\mathrm{mmol} / \mathrm{L})$, leukocytes $\left(\times 10^{9} / \mathrm{L}\right)$, thrombocytes $\left(\times 10^{9} / \mathrm{L}\right)$, and hemoglobin $(\mathrm{g} / \mathrm{L})$. 
Please refer to the Appendix A for details on laboratory assessments.

\subsection{Outcomes}

The primary outcome was the validity of the risk score predicting the probability of in-hospital mortality (death between presentation to the ED and discharge). Secondary outcomes were hospitalization and intensive care unit (ICU) admission.

Hospitalization was defined as admission to any hospital ward from the ED with a minimum of one overnight stay.

ICU-admission was defined as transfer to a medical or surgical ICU, intermediate care unit, or stroke unit during index hospitalization.

\subsection{Data Analysis}

Descriptive analyses are presented as medians with interquartile ranges for continuous variables and counts with percentages for categorical variables. Baseline characteristics and outcomes of patients included were compared to those of patients without laboratory data and $t$-test and chi-squared test were used to assess differences. Furthermore, the distribution of outcomes across the ESI levels was investigated. We used the statistical software R (Version 3.6.1, R Foundation for Statistical Computing, FreeSoftware Foundation, Boston, MA, USA) for all predictive calculations.

\subsubsection{Derivation of Predictive Models}

Four models were developed using multivariable logistic regression and their predictive performances for probability of in-hospital mortality were compared. (A) The baseline model included demographic data (age and gender) and triage category (ESI). (B) The laboratory model included all laboratory parameters tested (sodium, potassium, urea, creatinine, bilirubin, aspartate transaminase, lactate dehydrogenase, albumin, C-reactive protein, glucose, leukocytes, thrombocytes, and hemoglobin). All laboratory parameters except sodium and hemoglobin were log-transformed due to asymmetrical distribution. Restricted cubic splines [25] were used for all laboratory parameters to account for nonlinear relationships between the individual variables and in-hospital mortality on the log-odds scale. These variables with nonlinear relationships to the outcome were inserted in a logistic regression model and based on the log-odds the probability of in-hospital mortality was calculated. (C) The full model included all laboratory and baseline parameters, combining models A and B. (D) The reduced model included a reduced set of laboratory and baseline data, reducing the complexity of model C. Based on the full model, the combination of laboratory and baseline parameters with the best predictive validity was selected using stepwise backwards elimination [26]. We used AIC (Akaike information criterion) as a selection criterion. Backwards elimination starts with the full model and at each step the variable which increases the AIC the most gets eliminated. It stops if any of the remaining variables would decrease the AIC. The aim was to create a score with a minimal number of variables without losing predictive power.

Discriminatory validity of the models was evaluated with receiver operating characteristic (ROC) curves and their areas under the curve (AUC) with 95\% confidence intervals (CI). DeLong's test [27] was used to compare the models. The AUCs were adjusted for overfitting using bootstrapping. Additionally, we performed a 10-fold internal cross validation.

Calibration of the models was assessed by plotting the predicted probabilities versus the actual probabilities of in-hospital mortality.

\subsubsection{Development of the TRIAL Score}

For clinical usability, we chose the acronym TRIAL containing the three main categories (TRIage level, Age, Lab). Using the selected variables of the reduced model, we created a nomogram (calculating outcome probabilities based on predictor variables). Based on nonlinear logistic regression, predictor variables were mapped on a point scale according to the relative contribution of their values to the predicted in-hospital mor- 
tality. The likelihood of in-hospital mortality was predicted by the number of points a patient received.

Two risk cut-offs were selected by experts based on clinical usefulness for disposition decisions. They were set at $1 \%$ and $10 \%$ probability of in-hospital mortality, stratifying to low risk $(<1 \%)$, intermediate risk (1-10\%) and high risk $(>10 \%)$ - "low risk" representing patients safe for discharge, "intermediate risk" patients to be hospitalized, and "high risk" patients to be monitored in intermediate or intensive care units.

In addition, we evaluated the predictive performance of the variables of our score fitted for the secondary outcomes hospitalization and ICU-admission. Predictive validity was assessed with areas under the receiver operating characteristic curves.

\section{Results}

\subsection{Characteristics}

During the study period, 17,327 patients presented to the ED. Out of 14,440 enrolled patients, we excluded 17 patients due to missing ESI levels and 5736 patients without laboratory data. This resulted in 8687 patients (see Figure 1 for details).

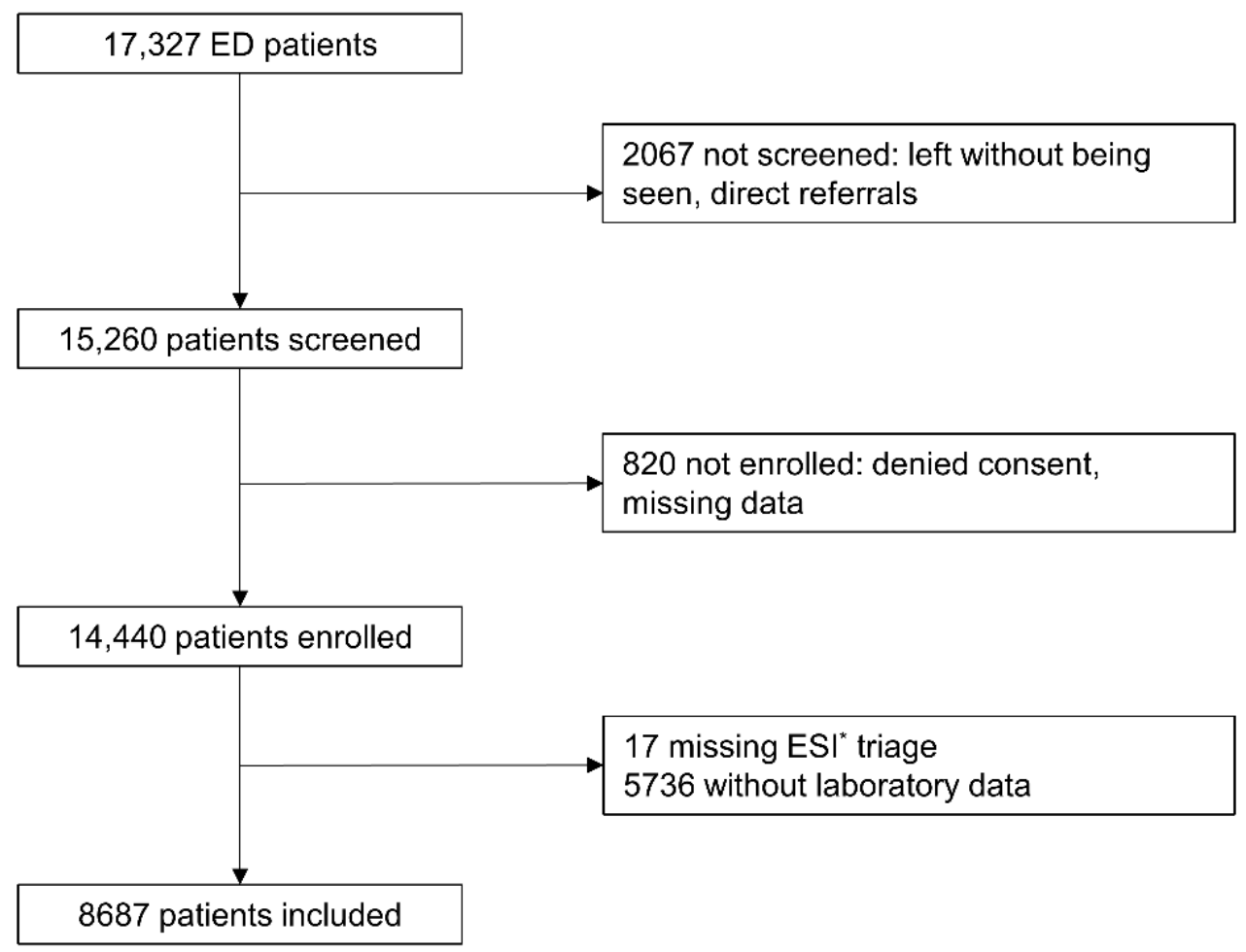

Figure 1. Inclusion procedure. ED: Emergency Department; * ESI = Emergency Severity Index.

Their median age was 61 years (IQR $42-78$ years) and 51.5\% were male. Most were classified as ESI $3(51.7 \%)$ and ESI 2 (37.3\%). In addition, 183 patients died in hospital (2.1\%), 4623 patients were hospitalized (53.2\%), and 758 patients (8.7\%) received ICU care.

Patients without laboratory data were younger, had lower acuity ESI levels, and better outcomes (see Table 1). 
Table 1. Baseline characteristics and outcomes of patients included and patients without laboratory data.

\begin{tabular}{|c|c|c|c|}
\hline & $\begin{array}{l}\text { All Patients } \\
(n=14,423)\end{array}$ & $\begin{array}{l}\text { Patients Included } \\
\quad(n=8687)\end{array}$ & $\begin{array}{c}\text { Patients without Laboratory } \\
\text { Data }(n=5736)\end{array}$ \\
\hline Age, median (IQR *) & $52(34-72)$ & $61(42-78)^{\S}$ & $40(29-56)^{\S}$ \\
\hline Male gender, $n(\%)$ & $7547(52.3)$ & $4471(51.5) \|$ & $3076(53.6) \|$ \\
\hline $\mathrm{ESI}^{\dagger}$ level & & $\S$ & $\S$ \\
\hline ESI $1, n(\%)$ & $339(2.4)$ & $320(3.7)$ & $19(0.3)$ \\
\hline ESI $2, n(\%)$ & $3562(24.7)$ & $3244(37.3)$ & $318(5.5)$ \\
\hline ESI $3, n(\%)$ & $5939(41.2)$ & $4492(51.7)$ & $1447(25.2)$ \\
\hline ESI $4, n(\%)$ & $4243(29.4)$ & $623(7.2)$ & $3620(63.1)$ \\
\hline ESI 5, $n(\%)$ & $340(2.4)$ & $8(0.1)$ & $332(5.8)$ \\
\hline In-hospital mortality, $n(\%)$ & $197(1.4)$ & $183(2.1) \S$ & $14(0.2) \S$ \\
\hline Hospitalization, $n(\%)$ & $4986(34.6)$ & $4623(53.2) \S$ & $363(6.3) \S$ \\
\hline ICU $\ddagger$ admsission, $n(\%)$ & $791(5.5)$ & $758(8.7) \S$ & $33(0.6)^{\S}$ \\
\hline
\end{tabular}

Data are presented as medians with interquartile ranges for continuous variables and counts with percentages for categorical variables. * $\mathrm{IQR}=$ interquartile range, ${ }^{\dagger}$ ESI $=$ Emergency Severity Index,${ }^{\ddagger} \mathrm{ICU}=$ intensive care unit,$\$$ Patients included and patients without laboratory data differ with a $p$-value $<0.001$, $\|$ Patients included and patients without laboratory data differ with a $p$-value of 0.01 .

Fourteen patients with missing or delayed laboratory analyses died (see Table A1).

Characteristics and outcomes were stratified by ESI level. In-hospital mortality gradually decreased from ESI 1 to 5. A similar decrease was observed for ICU-admissions and hospitalizations (see Table 2).

Table 2. Demographics and outcomes of patients included stratified by ESI level (1-5)

\begin{tabular}{cccccc}
\hline & $\begin{array}{c}\text { Age, Median } \\
(\text { IQR } *)\end{array}$ & $\begin{array}{c}\text { Male Gender } \\
\boldsymbol{n} \mathbf{( \% )}\end{array}$ & $\begin{array}{c}\text { Hospitalization } \\
\boldsymbol{n} \mathbf{( \% )}\end{array}$ & $\begin{array}{c}\text { ICU } \\
\text {-Admission } \\
\boldsymbol{n} \mathbf{( \% )}\end{array}$ & $\begin{array}{c}\text { Mortality } \\
\boldsymbol{( \% )}\end{array}$ \\
\hline ESI 1 & $69(55-79)$ & $194(60.6)$ & $295(92.2)$ & $180(56.3)$ & $61(19.1)$ \\
ESI 2 & $62(45-78)$ & $1758(54.2)$ & $1999(61.6)$ & $391(12.1)$ & $67(2.1)$ \\
ESI 3 & $61(40-79)$ & $2192(48.8)$ & $2166(48.2)$ & $177(3.9)$ & $54(1.2)$ \\
ESI 4 & $45(32-66)$ & $321(51.5)$ & $160(25.7)$ & $9(1.4)$ & $1(0.2)$ \\
ESI 5 & $41(28-72)$ & $6(75.0)$ & $3(37.5)$ & $1(12.5)$ & $0(0.0)$ \\
\hline
\end{tabular}

Data are presented as medians with interquartile ranges for continuous variables and counts with percentages for categorical variables.

${ }^{*} \mathrm{IQR}=$ interquartile range, ${ }^{\dagger} \mathrm{ICU}=$ intensive care unit, ${ }^{\ddagger} \mathrm{ESI}=$ Emergency Severity Index.

One ESI 4 patient died, and 10 ESI 4/5 patients were transferred to ICU (see Table A2).

\subsection{Performance of Predictive Models}

The predictive performance of the four models (baseline model, laboratory model, full model, and reduced model) regarding probability of in-hospital mortality is shown in Figure 2.

The baseline model's AUC was 0.86 (95\% CI 0.83-0.88), the laboratory model's AUC was 0.90 (95\% CI 0.88-0.92), and the full model's AUC was 0.94 (95\% CI 0.93-0.95). Stepwise backwards elimination reduced the full model to seven variables: Age, ESI, albumin, lactate dehydrogenase, leukocytes, creatinine, and bilirubin (nonlinear relationships to the probability of in-hospital mortality on the log-odds scale are shown in Figure A1). The reduced model's AUC was 0.93 (95\% CI 0.91-0.94).

After adjustment for overfitting AUCs was 0.85 for the baseline model, 0.88 for the laboratory model, 0.92 for the full model, and 0.91 for the reduced model. Results from 10 -fold internal cross validation are shown in the Appendix A. Comparison of the models using DeLong's test is shown in Table A3.

The reduced model predicted in-hospital mortality accurately up to a risk of $20 \%$ (see Figure A2). For higher probabilities of death, the reduced model showed an overestimation of the predicted in-hospital mortality. Of all patients, $132(1.5 \%)$ had an estimated mortality of more than $20 \%$. 


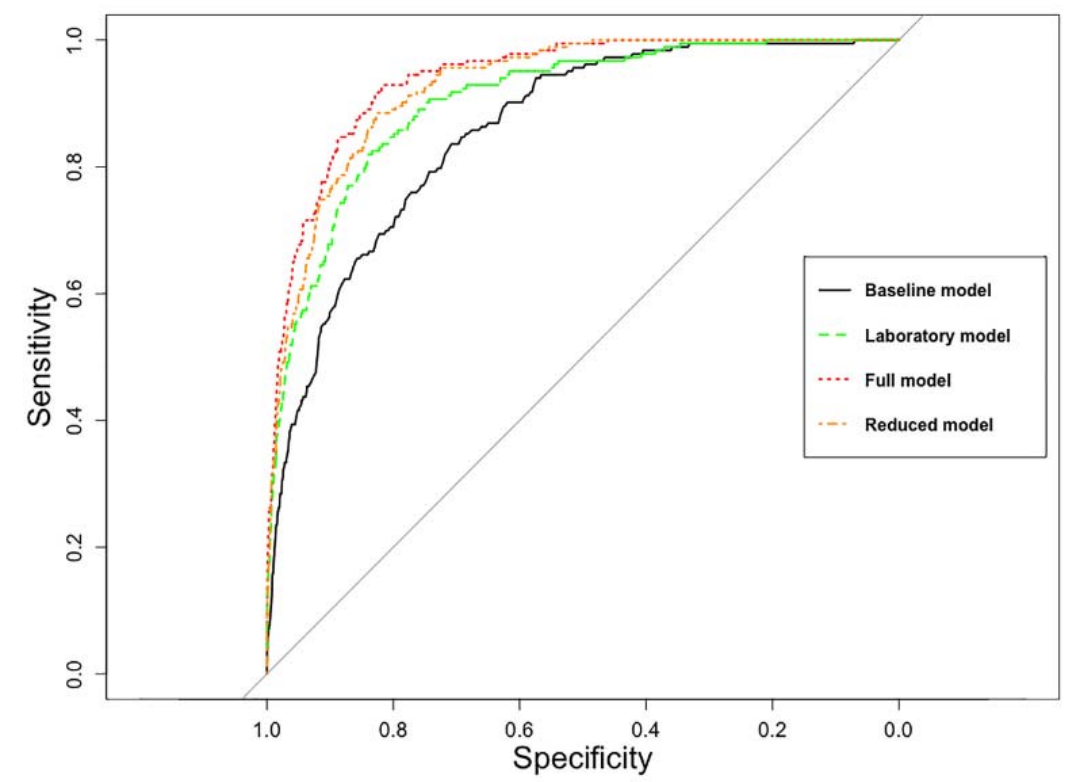

Figure 2. Comparison of the four multivariable logistic regression models regarding probability of in-hospital mortality. The area under the curve was 0.86 (95\% CI 0.83-0.88) for the baseline model, 0.90 (95\% CI 0.88-0.92) for the laboratory model, 0.94 (95\% CI 0.93-0.95) for the full model, and 0.93 (95\% CI 0.91-0.94) for the reduced model.

\subsection{TRIAL Risk Score}

The TRIAL risk score is shown in Table 3. Results exactly between two values are to be assigned to the value contributing a higher number of points. The low-risk cut-off ( $1 \%$ mortality) is at 145 points, and the high-risk cut-off ( $10 \%$ mortality) at 176 points.

Table 3. TRIAL score for prediction of in-hospital mortality.

\begin{tabular}{|c|c|c|c|c|c|c|c|c|c|c|c|c|c|c|}
\hline $\begin{array}{l}\text { Age (years) } \\
\text { Points }\end{array}$ & $\begin{array}{c}10 \\
0\end{array}$ & $\begin{array}{c}20 \\
9\end{array}$ & $\begin{array}{l}30 \\
18\end{array}$ & $\begin{array}{l}40 \\
27\end{array}$ & $\begin{array}{l}50 \\
35\end{array}$ & $\begin{array}{l}60 \\
42\end{array}$ & $\begin{array}{l}70 \\
46\end{array}$ & $\begin{array}{l}80 \\
51\end{array}$ & $\begin{array}{l}90 \\
59\end{array}$ & $\begin{array}{l}100 \\
68\end{array}$ & & & & \\
\hline ESI * (levels) & 5 & 4 & 3 & 2 & 1 & & & & & & & & & \\
\hline Points & 0 & 52 & 65 & 72 & 100 & & & & & & & & & \\
\hline $\begin{array}{l}\text { Creatinine } \\
\text { (umol/L) }\end{array}$ & 10 & 20 & 30 & 40 & 50 & 60 & 70 & 80 & 90 & 100 & 500 & & & \\
\hline Points & 44 & 26 & 16 & 9 & 4 & 0 & 0 & 3 & 6 & 9 & 14 & & & \\
\hline $\mathrm{LDH}^{\dagger}(\mathrm{U} / \mathrm{L})$ & 200 & 300 & 400 & 500 & 600 & 700 & 800 & 900 & 1000 & 1100 & 1200 & & & \\
\hline Points & 0 & 9 & 13 & 16 & 18 & 21 & 22 & 24 & 25 & 26 & 28 & & & \\
\hline Albumin (g/L) & 50 & 45 & 40 & 35 & 30 & 25 & 20 & 15 & & & & & & \\
\hline Points & 0 & 5 & 10 & 17 & 22 & 29 & 37 & 47 & & & & & & \\
\hline $\begin{array}{c}\text { Leukocytes } \\
\left(\times 10^{9} / \mathrm{L}\right)\end{array}$ & 1 & 2 & 3 & 4 & 5 & 10 & 15 & 20 & 25 & 30 & 35 & 40 & 45 & 50 \\
\hline Points & 23 & 13 & 7 & 3 & 0 & 0 & 4 & 7 & 10 & 12 & 13 & 15 & 16 & 17 \\
\hline $\begin{array}{l}\text { Bilirubin } \\
(\mu \mathrm{mol} / \mathrm{L})\end{array}$ & 2 & 5 & 10 & 20 & 30 & 40 & 50 & 60 & 70 & 80 & 90 & 100 & 110 & 120 \\
\hline Points & 5 & 1 & 0 & 4 & 8 & 11 & 14 & 16 & 18 & 19 & 21 & 22 & 23 & 24 \\
\hline Total points & 145 & 176 & & & & & & & & & & & & \\
\hline $\begin{array}{c}\text { Risk of } \\
\text { mortality }\end{array}$ & $1 \%$ & $10 \%$ & & & & & & & & & & & & \\
\hline
\end{tabular}


For the low-risk cut-off ( $1 \%)$, sensitivity was 0.96 , specificity 0.71 , negative predictive value 0.99 , and positive predictive value 0.067 regarding mortality prediction. For the high-risk cut-off (10\%), sensitivity was 0.54 , specificity 0.97 , negative predictive value 0.99 , and positive predictive value 0.26 regarding mortality prediction.

Patients were stratified according to ESI (1-5) and risk of death (see Table 4).

Table 4. Patients stratified according to ESI level (1-5) and risk of death.

\begin{tabular}{|c|c|c|c|c|c|c|}
\hline \multirow[b]{2}{*}{ All } & \multicolumn{2}{|c|}{ Total, $n(\%)$} & \multicolumn{2}{|c|}{$\begin{array}{c}\text { Non-Survivors, } n \\
(\%)\end{array}$} & \multicolumn{2}{|c|}{ Survivors, $n(\%)$} \\
\hline & 8687 & $(100.0)$ & & & & \\
\hline High risk & 344 & $(4.0)$ & 90 & $(26.2)$ & 254 & $(73.8)$ \\
\hline Intermediate risk & 2478 & $(28.5)$ & 86 & $(3.5)$ & 2392 & (96.5) \\
\hline Low risk & 5865 & $(67.5)$ & 7 & $(0.1)$ & 5858 & (99.9) \\
\hline $\mathrm{ESI} * 1$ & 320 & $(100.0)$ & & & & \\
\hline High risk & 173 & $(54.1)$ & 53 & $(30.6)$ & 120 & $(69.4)$ \\
\hline Intermediate risk & 127 & $(39.7)$ & 8 & $(6.3)$ & 119 & (93.7) \\
\hline Low risk & 20 & $(6.3)$ & 0 & $(0.0)$ & 20 & $(100.0)$ \\
\hline ESI 2 & 3244 & $(100.0)$ & & & & \\
\hline High risk & 111 & $(3.4)$ & 23 & $(20.7)$ & 88 & (79.3) \\
\hline Intermediate risk & 1147 & $(35.4)$ & 41 & $(3.6)$ & 1106 & (96.4) \\
\hline Low risk & 1986 & $(61.2)$ & 3 & $(0.2)$ & 1983 & (99.8) \\
\hline ESI 3 & 4492 & $(100.0)$ & & & & \\
\hline High risk & 60 & $(1.3)$ & 14 & $(23.3)$ & 46 & $(76.7)$ \\
\hline Intermediate risk & 1184 & $(26.4)$ & 37 & $(3.1)$ & 1147 & (96.9) \\
\hline Low risk & 3248 & $(72.3)$ & 3 & $(0.1)$ & 3245 & (99.9) \\
\hline ESI 4 & 623 & $(100.0)$ & & & & \\
\hline High risk & 0 & $(0.0)$ & 0 & $(0.0)$ & 0 & $(0.0)$ \\
\hline Intermediate risk & 20 & (3.2) & 0 & $(0.0)$ & 20 & $(100.0)$ \\
\hline Low risk & 603 & $(96.8)$ & 1 & $(0.2)$ & 602 & (99.8) \\
\hline ESI 5 & 8 & $(100.0)$ & & & & \\
\hline High risk & 0 & $(0.0)$ & 0 & $(0.0)$ & 0 & $(0.0)$ \\
\hline Intermediate risk & 0 & $(0.0)$ & 0 & $(0.0)$ & 0 & $(0.0)$ \\
\hline Low risk & 8 & $(100.0)$ & 0 & $(0.0)$ & 8 & $(100.0)$ \\
\hline
\end{tabular}

Patients are stratified according to ESI level (1-5) and their predicted risk of in-hospital mortality (low, intermediate, and high risk). Furthermore, the number and percentage of patients who died in-hospital in each risk group is shown per ESI level. * ESI = Emergency Severity Index.

Overall, 344 patients (4.0\%) were assigned to high risk, 2478 (28.5\%) to intermediate risk, and $5865(67.5 \%)$ to low risk. Mortality was $26.2 \%$ in the high-risk group, $3.5 \%$ in the intermediate-risk group, and $0.1 \%$ in the low-risk group.

The distribution of patients across the risk groups stratified by ESI level was as follows: The majority of ESI 1 patients (54.1\%) were assigned to the high-risk group (mortality $30.6 \%)$. High-risk was attributed to 111 patients with ESI $2(3.4 \%)$ and 60 patients with ESI 3 (1.3\%). Mortality was 20.7\% (ESI 2) and 23.3\% (ESI 3), respectively. No ESI 4 or 5 patients were classified as high-risk patients. The low-risk group comprised $67.5 \%$ of all patients and mortality was $0.1 \%$ (7 deaths of 5865 low-risk cases, see Table A4), which was similar across all ESI levels. Deaths in the laboratory-based low-risk group were found in aortic dissection $(n=3)$, COPD exacerbation $(n=1)$, pneumonia $(n=1)$, subdural hematoma $(n=1)$, and suicide $(n=1)$.

Predictive validity of the variables of the reduced model fitted for secondary outcomes was good with AUCs of 0.80 for hospitalization and 0.81 for intensive care (details in Table A5). 


\section{Discussion}

Baseline and routine laboratory parameters may be used for outcome prediction supporting disposition decisions. The main findings of this study are that the predictive validity is excellent regarding mortality and good regarding intensive care, that two thirds of all patients can be attributed to the low-risk category, and that the derived TRIAL risk score could support early disposition decisions.

Health care systems around the globe have reported a public hospital bed crisis [28-30] and many approaches were considered, such as the implementation of guidelines to reduce hospital length of stay [31], comprehensive geriatric interventions [32], or early discharge [33], in order to reduce the economic burden of over-hospitalization. The absence of evidence-based guidelines for admission avoidance [33,34] may be due to a lack of published evidence focusing on disposition after emergency work-up. Because public hospitals tend to admit the majority of acutely ill patients from their emergency departments, they are directly affected by disposition decisions after emergency work-up.

The study's results show that such disposition decisions may be facilitated using laboratory data because risk stratification can be based on a score, both for the all-comer cohort and for each triage level separately. Even in the second highest triage acuity level (ESI 2) with admission rates of $62 \%$ (our data) to $73 \%$ [35], most patients had a low risk of mortality and could theoretically have been discharged for this reason. While ESI is the best validated triage tool, risk stratification according to ESI may be of limited use because of its focus on "acuity" and the large overlap in prognosis, particularly between the highly prevalent ESI 2 and ESI 3 cohorts. Laboratory data are available for most ESI 2 and ESI 3 patients, and the TRIAL score can significantly improve the precision of risk stratification within each ESI level. In fact, the isolated laboratory model outperformed the baseline model, only to be topped by the full model and the reduced TRIAL model. While most of the parameters are known to be of prognostic value, the combination of the parameters was never assessed in an all-comer cohort. In detail, age and ESI [3,20], albumin [36], lactate dehydrogenase [37], leukocytes [11], bilirubin [11], and high levels of creatinine [38] are of prognostic value in emergency cohorts. Association between low creatinine levels and unfavorable outcome was only shown in intensive care patients $[39,40]$. Previous reports on the predictive value of laboratory parameters (lab) have shown similar results, but some were based only on lab [38,41], others on the combination of lab and less used triage tools $[37,42]$, the latter showing only marginally improved predictive power if adding lab to the baseline model. Most attempts did not serve the purpose of directly supporting disposition decisions but were designed to provide relative risks, e.g., in admitted patients [12]. With our expert-based decision to choose cut-offs of $1 \%$ and $10 \%$ for admission and observation, respectively, we aimed at supporting disposition decisions directly. The advantage of this approach is the usability under different circumstances and with adjusted cut-offs. For example, in low-resource environments, cut-offs may be adjusted. In situations suitable for shared decision-making, patients may be informed about their prognosis in order to agree on disposition. The potential benefit of this approach depends less on the data set used for calculation, but in the feasibility of a risk calculation based on an all-comer cohort with lab parameters and cut-offs for disposition decisions agreed upon locally, or even individually.

Taken together, the negative predictive value of 0.99 for mortality at the $1 \%$ cut-off provides safety for early discharge. By avoiding dichotomizing variables using reference values, the loss of information can be minimized [43]. By using the TRIAL score based on points attributed to each variable, risk assessment can be made transparent and easy to understand. Finally, calibration is good up to a mortality of $20 \%$, the cut-off for high-risk patients being set at $10 \%$. There is also a potential to identify patients at risk at an early stage-allocating resources for their observation potentially improving outcomes. 


\section{Limitations}

This is a single-center all-comer cohort. Therefore, external validity is limited. The risk of short-term mortality is not the only reason to be admitted. In addition, pain, dyspnea, impaired function, and psychosocial aspects may mandate hospitalization. We did not investigate causes for admission systematically, e.g., by asking patients about their preferences. However, the study was designed as a proof-of-principle approach. Any institution with access to emergency, laboratory, and outcome-data could use the methods described to calculate their individual risk score in lieu of the proposed TRIAL score and decide on meaningful cut-offs for discharge, admission, and observation.

Furthermore, there is a potential selection bias due to excluding patients with no complete set of laboratory data. However, more than two-thirds (69\%) of excluded patients were assigned to ESI 4 and 5. Patients without laboratory had an overall survival of 99.8\%, and ESI $4 / 5$ patients without laboratory had a survival of $100 \%$. Doubts could also be raised about the potential use of a laboratory-based score in ESI 1 patients undergoing highly standardized life-saving interventions with subsequent observation in most cases. Similarly, ESI 4/5 patients with low admission rates may not need such a score. However, the largest groups (ESI 2 and ESI 3), in which low-risk patients dominate, may profit the most, as these patients tend to be hospitalized for fear of unfavorable outcomes. Finally, mortality could be underestimated because almost half of the patients were discharged. However, 30-day observation of the first 4190 patients showed similar results with a very low post-discharge mortality. Another limitation is the missing analysis of patients during the summer months July-September.

\section{Conclusions}

This is a proof-of-principle study aiming at disposition decision support to minimize unnecessary admissions in low-risk patients and maximize observation in high-risk patients, irrespective of diagnoses. This approach needs to be tested in an intervention trial, in order to put this evidence on a solid foundation for the benefit of patients and health care systems.

Author Contributions: Conceptualization, C.H.N. and R.B.; Formal analysis, O.S.M.; Methodology, O.S.M., K.M.R., C.H.N. and R.B.; Project administration, R.B.; Supervision, C.H.N. and R.B.; Writingoriginal draft, O.S.M., C.H.N. and R.B.; All authors have read and agreed to the published version of the manuscript.

Funding: This research was supported by Scientific Funds of the University Hospital Basel (Grant number FO112801).

Institutional Review Board Statement: The study was conducted according to the guidelines of the Declaration of Helsinki, and approved by the Ethics Committee of EKNZ (EKNZ-236/13; www.eknz.ch, accessed date: 12 December 2019).

Informed Consent Statement: Informed consent was obtained from all patients able to provide consent. For patients unable to provide consent, the need for informed consent was waived by the ethics committee according to article 34 HFG. We excluded patients if the electronic health record (EHR) contained a general rejection to participate in research.

Data Availability Statement: The data presented in this study are available on request from the corresponding author.

Acknowledgments: We thank all personnel involved in acquiring data. We thank Andreas Schötzau from Eudox Statistical Consulting and Nikolai Hodel for providing professional statistical analyses.

Conflicts of Interest: The authors declare no conflict of interest.

\section{Appendix A}

Details on laboratory assessments. Results from 10-fold internal cross validation. Table A1: Patients who died without laboratory data, Table A2: Patients with ESI levels 4 
or 5 admitted to the ICU, Table A3: Comparison of ROC* curves using DeLong's test, Table A4: Low-risk patients who died, Table A5: Predictive validity of the variables from the reduced model fitted for the secondary outcomes, Figure A1: Nonlinear relationships between variables of the reduced model and in-hospital mortality, Figure A2: Predicted probabilities versus actual probabilities of in-hospital mortality.

Details on Laboratory Assessments: Sodium and potassium were determined by ion selective electrodes (Roche, Rotkreuz, Switzerland). Enzymatic methods at $37^{\circ} \mathrm{C}$ were applied for the determination of urea (urease/glutamatdehydrogenase), creatinine (creatininase/creatinase/sarcosinoxidase), glucose (hexokinase/glucose-6-phosphate dehydrogenase), aspartate transaminase (IFCC, with pyridoxal phosphate), and lactate dehydrogenase. Colorimetric methods were used for bilirubin (diazo method) and albumin (bromocresol purple) and a turbidimetric assay for the quantification of C-reactive protein (2013: all Modular $p$ module, Roche, Rotkreuz, Switzerland; 2017/2019: all Cobas c702 module, Roche, Rotkreuz, Switzerland). The leukocyte and thrombocyte counts as well as the hemoglobin concentration were determined using an Advia 2120 instrument (Siemens Healthineers, Zürich, Switzerland). For laboratory values below or above detection limit, the detection limit was set as the value for analysis (e.g., a creatinine below $5 \mu \mathrm{mol} / \mathrm{L}$ $(0.057 \mathrm{mg} / \mathrm{dl})$ was defined as $5 \mu \mathrm{mol} / \mathrm{L})$.

Results from 10-fold cross validation: After performing 10-fold cross validation, AUCs were 0.85 for the baseline model, 0.88 for the laboratory model, 0.91 for the full model, and 0.91 for the reduced model.

Table A1. Patients who died without laboratory data.

\begin{tabular}{|c|c|c|c|c|}
\hline Cause of Death & Reason for Missing Laboratory & Age & Gender & ESI * \\
\hline $\begin{array}{l}\text { Gastrointestinal bleeding } \\
\text { with cardiac arrest }\end{array}$ & $\begin{array}{l}\text { Stop of resuscitation in } \\
\text { consultation with the } \\
\text { patient's family }\end{array}$ & 84 & $\mathrm{w}$ & 1 \\
\hline $\begin{array}{l}\text { 3rd degree burns ( } 90 \% \text { of } \\
\text { body surface) in } \\
\text { suicidal intent }\end{array}$ & $\begin{array}{l}\text { Not possible to intubate or to } \\
\text { perform a tracheotomy, no } \\
\text { resuscitation performed at } \\
\text { cardiac arrest }\end{array}$ & 61 & $\mathrm{~m}$ & 1 \\
\hline Cardiac arrest & $\begin{array}{l}\text { Unobserved cardiac arrest } \\
\text { outside the hospital, arrival in } \\
\text { resuscitation facility after } 90 \mathrm{~min} \\
\text { of resuscitation }\end{array}$ & 62 & $\mathrm{~m}$ & 1 \\
\hline Cardiogenic shock & $\begin{array}{l}\text { No resuscitation in accordance } \\
\text { with the patient's family }\end{array}$ & 97 & $\mathrm{w}$ & 2 \\
\hline $\begin{array}{l}\text { ST-segment elevation } \\
\text { myocardial infarction }\end{array}$ & $\begin{array}{l}\text { Resuscitation was stopped in } \\
\text { accordance with the living will }\end{array}$ & 76 & $\mathrm{w}$ & 1 \\
\hline $\begin{array}{l}\text { Cardiac arrest (10 days } \\
\text { after presentation) }\end{array}$ & $\begin{array}{l}\text { Analysis of glucose was missing. } \\
\text { The patient was transferred to } \\
\text { our ED }{ }^{\dagger} \text { and hospitalized for } \\
\text { suspicion of pleural empyema }\end{array}$ & 49 & $\mathrm{~m}$ & 3 \\
\hline Death by unknown causes & $\begin{array}{l}\text { Analysis of glucose was missing. } \\
\text { Patient was admitted with a } \\
\text { fracture of the humerus }\end{array}$ & 82 & $\mathrm{~m}$ & 3 \\
\hline $\begin{array}{l}\text { Septic shock due to } \\
\text { hospital-acquired } \\
\text { pneumonia ( } 5 \text { weeks } \\
\text { after admission) }\end{array}$ & $\begin{array}{l}\text { Analysis of glucose was missing. } \\
\text { Patient was transferred from } \\
\text { another hospital to our ED and } \\
\text { hospitalized for surgery the } \\
\text { next day }\end{array}$ & 65 & $\mathrm{~m}$ & 3 \\
\hline
\end{tabular}


Table A1. Cont.

\begin{tabular}{|c|c|c|c|c|}
\hline Cause of Death & Reason for Missing Laboratory & Age & Gender & ESI * \\
\hline $\begin{array}{l}\text { ST-segment elevation } \\
\text { myocardial infarction }\end{array}$ & $\begin{array}{c}\text { Analysis of AST } \ddagger \text { and } \mathrm{LDH}^{\S} \\
\text { impossible for hemolysis }\end{array}$ & 55 & $\mathrm{w}$ & 3 \\
\hline $\begin{array}{l}\text { Acute abdomen with } \\
\text { retroperitoneal and } \\
\text { gastrointestinal bleeding, } \\
\text { sudden worsening of } \\
\text { condition. No resuscitation } \\
\text { performed according to the } \\
\text { living will. }\end{array}$ & $\begin{array}{l}\text { Analysis of AST and LDH } \\
\text { impossible for hemolysis }\end{array}$ & 77 & $\mathrm{~m}$ & 3 \\
\hline Cardiac arrest & $\begin{array}{l}\text { Analysis of AST and LDH } \\
\text { impossible for hemolysis }\end{array}$ & 57 & $\mathrm{~m}$ & 1 \\
\hline $\begin{array}{c}\text { Mass hemorrhage in the left } \\
\text { hemisphere }\end{array}$ & $\begin{array}{l}\text { Analysis of AST and LDH } \\
\text { impossible for hemolysis }\end{array}$ & 81 & $\mathrm{~m}$ & 1 \\
\hline Aortic dissection type A & $\begin{array}{l}\text { Analysis of AST and LDH } \\
\text { impossible for hemolysis }\end{array}$ & 69 & $\mathrm{~m}$ & 1 \\
\hline Sepsis & $\begin{array}{l}\text { Analysis of AST and LDH } \\
\text { impossible for hemolysis }\end{array}$ & 82 & $\mathrm{~m}$ & 1 \\
\hline
\end{tabular}

Table A2. Patients with ESI levels 4 or 5 admitted to the ICU *.

\begin{tabular}{|c|c|c|c|c|}
\hline Presentation at Triage & Final Diagnosis & Age & Gender & $\mathrm{ESI}^{\dagger}$ \\
\hline $\begin{array}{l}\text { Fall without signs of } \\
\text { concussion }\end{array}$ & $\begin{array}{l}\text { Acute-on-chronic subdural } \\
\text { hematoma }\end{array}$ & 86 & $\mathrm{w}$ & $4 \ddagger$ \\
\hline Abdominal pain & Appendicitis & 47 & $\mathrm{~m}$ & 5 \\
\hline Infection of the finger & $\begin{array}{l}\text { Flexor tendon infection, } \\
\text { in-hospital acute coronary } \\
\text { syndrome }\end{array}$ & 79 & $\mathrm{~m}$ & 4 \\
\hline Change of behavior & $\begin{array}{l}\text { Shunt dysfunction (shunt of } \\
18 \text { years for hydrocephalus) }\end{array}$ & 64 & $\mathrm{w}$ & 4 \\
\hline Necrotic fingertip & $\begin{array}{l}\text { Multiple cerebral ischemic } \\
\text { infarctions }\end{array}$ & 63 & $\mathrm{w}$ & 4 \\
\hline $\begin{array}{l}\text { Loss of sensation in the left } \\
\text { foot in the last months, } \\
\text { worse since a few days }\end{array}$ & Glioblastoma multiforme & 78 & $\mathrm{~m}$ & 4 \\
\hline $\begin{array}{l}\text { Fall with multiple } \\
\text { contusions }\end{array}$ & Fractures and shoulder injury & 67 & $\mathrm{w}$ & 4 \\
\hline Infection of unknown origin & $\begin{array}{c}\text { Cerebrovascular infarction due to } \\
\text { embolism }\end{array}$ & 42 & $\mathrm{~m}$ & 4 \\
\hline $\begin{array}{l}\text { Transfer from another } \\
\text { hospital (suspicion of } \\
\text { mediastinal problem) }\end{array}$ & Acute osteomyelitis & 71 & $\mathrm{w}$ & 4 \\
\hline Dyspnea of unknown origin & Acute heart failure & 72 & $\mathrm{~m}$ & 4 \\
\hline
\end{tabular}

${ }^{*} \mathrm{ICU}=$ intensive care unit $^{\dagger}{ }^{\dagger}$ ESI $=$ Emergency Severity Index,${ }^{\ddagger}$ patient died in-hospital. 
Table A3. Comparison of ROC * curves using DeLong's test.

\begin{tabular}{ccc}
\hline First Model to Be Compared & Second Model to Be Compared & $p$-Value \\
\hline Baseline model & Laboratory model & 0.005 \\
\hline Baseline model & Full model & $<0.001$ \\
\hline Baseline model & Reduced model & $<0.001$ \\
\hline Laboratory model & Full model & $<0.001$ \\
\hline Laboratory model & Reduced model & 0.003 \\
\hline Full model & Reduced model & 0.002 \\
\hline
\end{tabular}

${ }^{*} \mathrm{ROC}=$ receiver operating characteristic.

Table A4. Low-risk patients who died.

\begin{tabular}{cccc}
\hline Cause of Death & Gender & Age & ESI $^{*}$ \\
\hline Exacerbation of COPD $^{+}$ & $\mathrm{w}$ & 61 & 2 \\
\hline Aortic dissection & $\mathrm{m}$ & 39 & 2 \\
\hline Aortic dissection & $\mathrm{m}$ & 56 & 2 \\
\hline Committed suicide during hospital stay & $\mathrm{w}$ & 69 & 3 \\
\hline Aortic dissection & $\mathrm{w}$ & 84 & 3 \\
\hline Pneumonia (possibly due to aspiration) & $\mathrm{m}$ & 70 & 3 \\
\hline Acute on chronic subdural hematoma & $\mathrm{w}$ & 86 & 4 \\
\hline
\end{tabular}

* ESI = Emergency Severity Index,${ }^{+} \mathrm{COPD}=$ chronic obstructive pulmonary disease.

Table A5. Predictive validity of the variables from the reduced model fitted for the secondary outcomes.

\begin{tabular}{ccc}
\hline Outcome & $\begin{array}{c}\text { Area under } \\
\text { the ROC* Curve }\end{array}$ & $\begin{array}{c}\text { Area under the ROC Curve } \\
\text { Adjusted with Bootstrapping }\end{array}$ \\
\hline Hospitalization & 0.80 & 0.80 \\
\hline Admission to an intensive care unit & 0.81 & 0.81 \\
\hline${ }^{*}$ ROC $=$ receiver operating characteristic. & &
\end{tabular}

${ }^{*}$ ROC $=$ receiver operating characteristic.
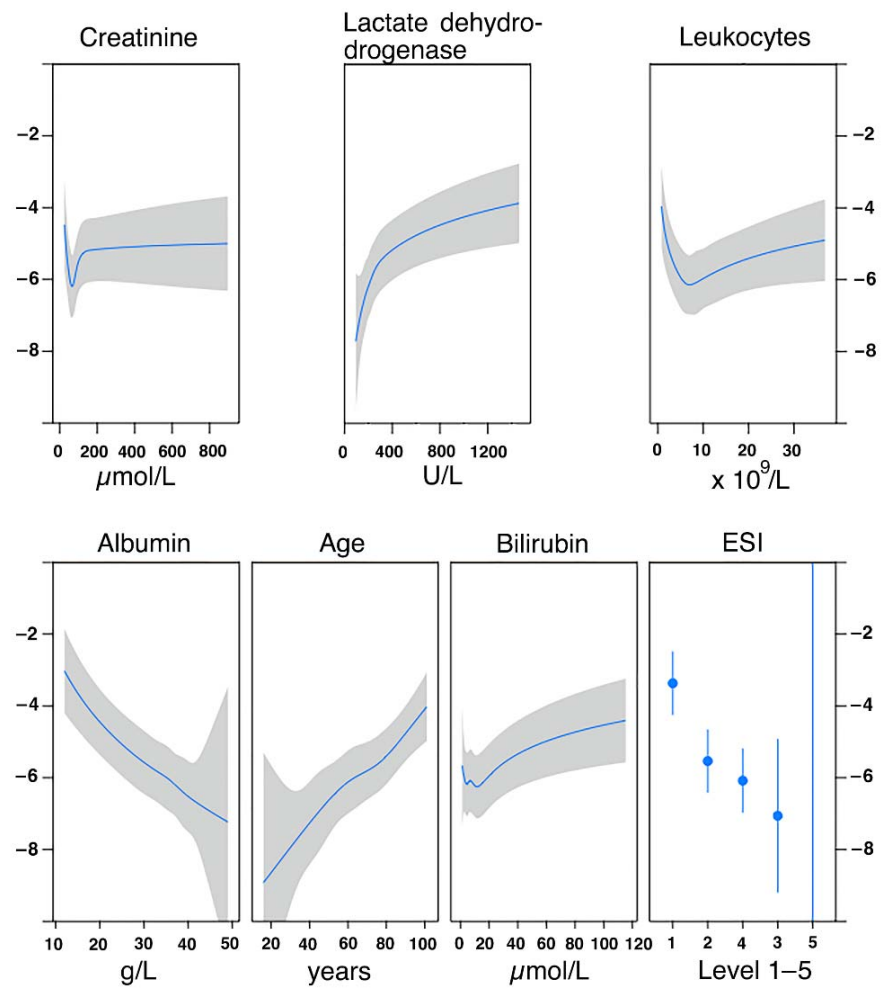

Figure A1. Nonlinear relationships between variables of the reduced model and probability of in-hospital mortality on a log odds scale. 

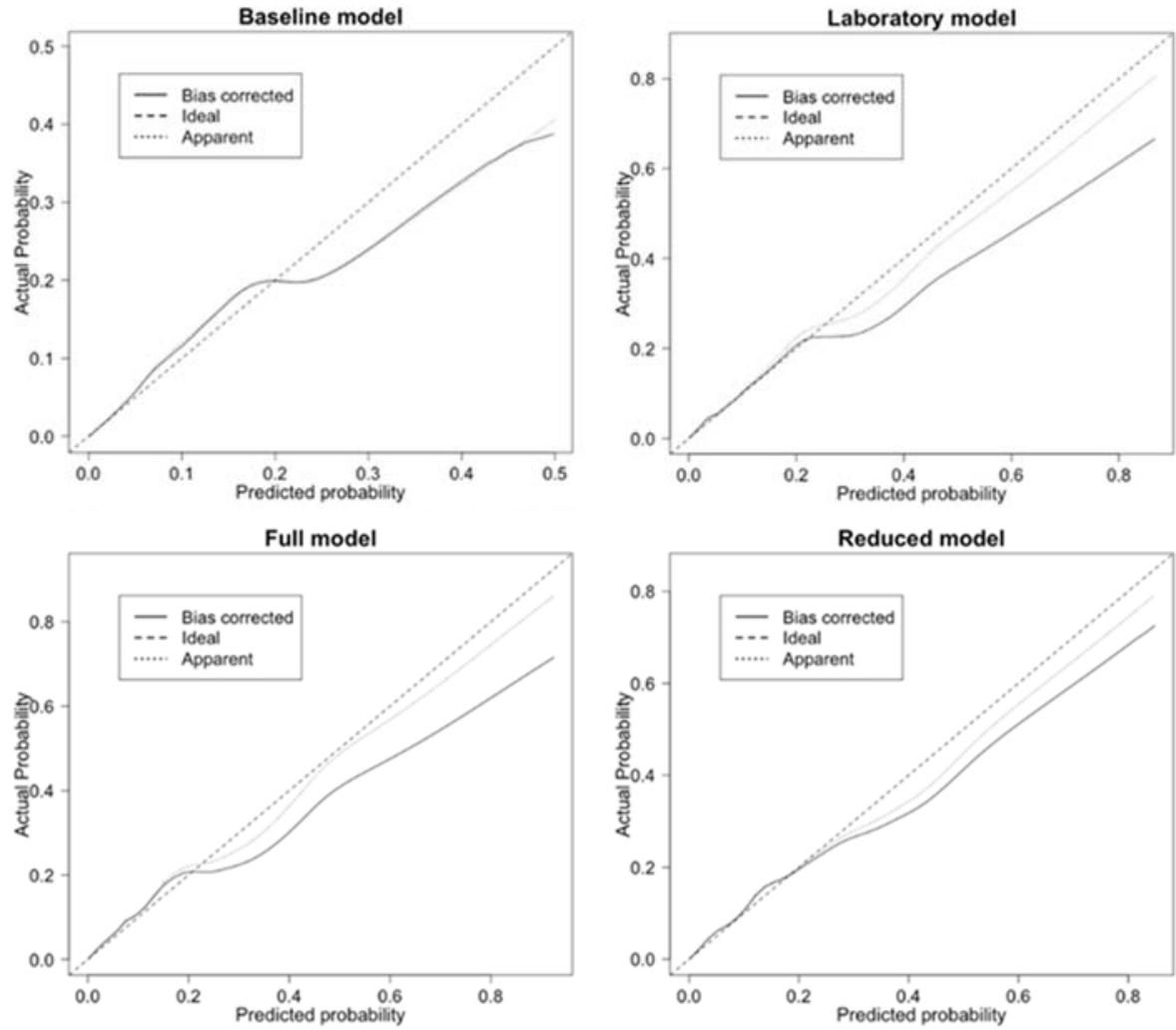

Figure A2. Predicted probabilities versus actual probabilities of in-hospital mortality. Apparent $=$ the model derived from multivariable logistic regression; bias-corrected = model adjusted for overfitting using bootstrapping.

\section{References}

1. Bingisser, R.; Nickel, C.H. The last decade of symptom-oriented research in emergency medicine: Triage, work-up, and disposition. Swiss Med. Wkly. 2019, 149, w20141. [CrossRef]

2. Obermeyer, Z.; Cohn, B.; Wilson, M.; Jena, A.B.; Cutler, D.M. Early death after discharge from emergency departments: Analysis of national US insurance claims data. BMJ 2017, 356, j239. [CrossRef] [PubMed]

3. Sun, Y.; Heng, B.H.; Tay, S.Y.; Seow, E. Predicting hospital admissions at emergency department triage using routine administrative data. Acad. Emerg. Med. 2011, 18, 844-850. [CrossRef]

4. Moore, C.C.; Hazard, R.; Saulters, K.J.; Ainsworth, J.; Adakun, S.A.; Amir, A.; Andrews, B.; Auma, M.; Baker, T.; Banura, P.; et al. Derivation and validation of a universal vital assessment (UVA) score: A tool for predicting mortality in adult hospitalised patients in sub-Saharan Africa. BMJ Glob. Health 2017, 2, e000344. [CrossRef] [PubMed]

5. Wheeler, I.; Price, C.; Sitch, A.; Banda, P.; Kellett, J.; Nyirenda, M.; Rylance, J. Early warning scores generated in developed healthcare settings are not sufficient at predicting early mortality in Blantyre, Malawi: A prospective cohort study. PLoS ONE 2013, 8, e59830. [CrossRef] [PubMed]

6. Nabayigga, B.; Kellett, J.; Brabrand, M.; Opio, M.O. The mortality of acutely ill medical patients for up to 60days after admission to a resource poor hospital in sub-Saharan Africa compared with patients of similar illness severity admitted to a Danish Regional Teaching Hospital-An exploratory observational study. Eur. J. Intern. Med. 2016, 27, 24-30.

7. Kellett, J.; Kim, A. Validation of an abbreviated Vitalpac ${ }^{\mathrm{TM}}$ Early Warning Score (ViEWS) in 75,419 consecutive admissions to a Canadian regional hospital. Resuscitation 2012, 83, 297-302. [CrossRef]

8. Misch, F.; Messmer, A.S.; Nickel, C.H.; Gujan, M.; Graber, A.; Blume, K.; Bingisser, R. Impact of observation on disposition of elderly patients presenting to emergency departments with non-specific complaints. PLoS ONE 2014, 9, e98097. [CrossRef] [PubMed]

9. Raita, Y.; Goto, T.; Faridi, M.K.; Brown, D.F.M.; Camargo, C.A.; Hasegawa, K., Jr. Emergency department triage prediction of clinical outcomes using machine learning models. Crit. Care 2019, 23, 64. [CrossRef]

10. Brabrand, M.; Lassen, A.T.; Knudsen, T.; Hallas, J. Seven-day mortality can be predicted in medical patients by blood pressure, age, respiratory rate, loss of independence, and peripheral oxygen saturation (the PARIS score): A prospective cohort study with external validation. PLoS ONE 2015, 10, e0122480. [CrossRef] 
11. Loekito, E.; Bailey, J.; Bellomo, R.; Hart, G.K.; Hegarty, C.; Davey, P.; Bain, C.; Pilcher, D.; Schneider, H. Common laboratory tests predict imminent medical emergency team calls, intensive care unit admission or death in emergency department patients. Emerg. Med. Australas. 2013, 25, 132-139. [CrossRef]

12. Asadollahi, K.; Hastings, I.M.; Gill, G.V.; Beeching, N.J. Prediction of hospital mortality from admission laboratory data and patient age: A simple model. Emerg. Med. Australas. 2011, 23, 354-363. [CrossRef] [PubMed]

13. Prytherch, D.R.; Sirl, J.S.; Schmidt, P.; Featherstone, P.I.; Weaver, P.C.; Smith, G.B. The use of routine laboratory data to predict in-hospital death in medical admissions. Resuscitation 2005, 66, 203-207. [CrossRef] [PubMed]

14. Froom, P.; Shimoni, Z. Prediction of hospital mortality rates by admission laboratory tests. Clin. Chem. 2006, 52, 325-328. [CrossRef] [PubMed]

15. Redfern, O.C.; Pimentel, M.A.F.; Prytherch, D.; Meredith, P.; Clifton, D.A.; Tarassenko, L.; Smith, G.B.; Watkinson, P.J. Predicting in-hospital mortality and unanticipated admissions to the intensive care unit using routinely collected blood tests and vital signs: Development and validation of a multivariable model. Resuscitation 2018, 133, 75-81. [CrossRef] [PubMed]

16. Riordan, J.P.; Dell, W.L.; Patrie, J.T. Can Patient Variables Measured on Arrival to the Emergency Department Predict Disposition in Medium-acuity Patients? J. Emerg. Med. 2017, 52, 769-779. [CrossRef]

17. Nickel, C.H.; Messmer, A.S.; Geigy, N.; Misch, F.; Mueller, B.; Dusemund, F.; Hertel, S.; Hartmann, O.; Giersdorf, S.; Bingisser, R. Stress markers predict mortality in patients with nonspecific complaints presenting to the emergency department and may be a useful risk stratification tool to support disposition planning. Acad. Emerg. Med. 2013, 20, 670-679. [CrossRef] [PubMed]

18. Dinh, M.M.; Russell, S.B.; Bein, K.J.; Rogers, K.; Muscatello, D.; Paoloni, R.; Hayman, J.; Chalkley, D.R.; Ivers, R. The Sydney Triage to Admission Risk Tool (START) to predict Emergency Department Disposition: A derivation and internal validation study using retrospective state-wide data from New South Wales, Australia. BMC Emerg Med. 2016, 16, 46. [CrossRef]

19. Kellett, J.; Nickel, C.H.; Skyttberg, N.; Brabrand, M. Is it possible to quickly identify acutely unwell patients who can be safely managed as outpatients? The need for a "Universal Safe to Discharge Score". Eur. J. Intern. Med. 2019, 67, e13-e15. [CrossRef]

20. Grossmann, F.F.; Nickel, C.H.; Christ, M.; Schneider, K.; Spirig, R.; Bingisser, R. Transporting clinical tools to new settings: Cultural adaptation and validation of the Emergency Severity Index in German. Ann. Emerg. Med. 2011, 57, 257-264. [CrossRef] [PubMed]

21. Parker, C.A.; Liu, N.; Wu, S.X.; Shen, Y.; Lam, S.S.W.; Ong, M.E.H. Predicting hospital admission at the emergency department triage: A novel prediction model. Am. J. Emerg. Med. 2019, 37, 1498-1504. [CrossRef]

22. Bingisser, R.; Baerlocher, S.M.; Kuster, T.; Nieves Ortega, R.; Nickel, C.H. Physicians' Disease Severity Ratings are Non-Inferior to the Emergency Severity Index. J. Clin. Med. 2020, 9, 762. [CrossRef]

23. Gilboy, N.; Tanabe, P.; Travers, D.A.; Rosenau, A.M.; Eitel, D.R. Emergency Severity Index, Version 4, Implementation Handbook; Agency for Healthcare Research and Quality: Rockville, MD, USA, 2005; pp. 1-72.

24. Silke, B.; Kellett, J.; Rooney, T.; Bennett, K.; O’Riordan, D. An improved medical admissions risk system using multivariable fractional polynomial logistic regression modelling. QJM 2010, 103, 23-32. [CrossRef]

25. Harrell, F.E., Jr. Regression Modeling Strategies: With Applications to Linear Models, Logistic and Ordinal Regression, and Survival Analysis; Springer: Cham, Switzerland, 2015.

26. Lawless, J.F.; Singhal, K. Efficient Screening of Nonnormal Regression Models. Biometrics 1978, 34, 318-327. [CrossRef]

27. DeLong, E.R.; DeLong, D.M.; Clarke-Pearson, D.L. Comparing the areas under two or more correlated receiver operating characteristic curves: A nonparametric approach. Biometrics 1988, 44, 837-845. [CrossRef] [PubMed]

28. Scott, I.A. Public hospital bed crisis: Too few or too misused? Aust. Health Rev. 2010, 34, 317-324. [CrossRef]

29. Philp, I.; Mills, K.A.; Thanvi, B.; Ghosh, K.; Long, J.F. Reducing hospital bed use by frail older people: Results from a systematic review of the literature. Int. J. Integr. Care 2013, 13, e048. [CrossRef] [PubMed]

30. Darehed, D.; Norrving, B.; Stegmayr, B.; Zingmark, K.; Blom, M.C. Patients with acute stroke are less likely to be admitted directly to a stroke unit when hospital beds are scarce: A Swedish multicenter register study. Eur. Stroke J. 2017, 2, 178-186. [CrossRef]

31. Weingarten, S.; Riedinger, M.S.; Sandhu, M.; Bowers, C.; Ellrodt, A.G.; Nunn, C.; Hobson, P.; Greengold, N. Can practice guidelines safely reduce hospital length of stay? Results from a multicenter interventional study. Am. J. Med. 1998, 105, 33-40. [CrossRef]

32. Vidán, M.; Serra, J.A.; Moreno, C.; Riquelme, G.; Ortiz, J. Efficacy of a comprehensive geriatric intervention in older patients hospitalized for hip fracture: A randomized, controlled trial. J. Am. Geriatr. Soc. 2005, 53, 1476-1482. [CrossRef]

33. Hardy, C.; Whitwell, D.; Sarsfield, B.; Maimaris, C. Admission avoidance and early discharge of acute hospital admissions: An accident and emergency based scheme. Emerg. Med. J. 2001, 18, 435-440. [CrossRef] [PubMed]

34. Purdy, S.; Griffin, T. Reducing hospital admissions. BMJ 2008, 336, 4-5. [CrossRef]

35. Tanabe, P.; Gimbel, R.; Yarnold, P.R.; Kyriacou, D.N.; Adams, J.G. Reliability and validity of scores on The Emergency Severity Index version 3. Acad. Emerg. Med. 2004, 11, 59-65. [CrossRef] [PubMed]

36. Lyons, O.; Whelan, B.; Bennett, K.; O'Riordan, D.; Silke, B. Serum albumin as an outcome predictor in hospital emergency medical admissions. Eur. J. Intern. Med. 2010, 21, 17-20. [CrossRef] [PubMed]

37. Kristensen, M.; Iversen, A.K.S.; Gerds, T.A.; Østervig, R.; Linnet, J.D.; Barfod, C.; Lange, K.H.W.; Sölétormos, G.; Forberg, J.L.; Eugen-Olsen, J. Routine blood tests are associated with short term mortality and can improve emergency department triage: A cohort study of $>12,000$ patients. Scand. J. Trauma, Resusc. Emerg. Med. 2017, 25, 115. [CrossRef] 
38. Jarvis, S.W.; Kovacs, C.; Badriyah, T.; Briggs, J.; Mohammed, M.A.; Meredith, P.; Schmidt, P.E.; Featherstone, P.I.; Prytherch, D.R.; Smith, G.B. Development and validation of a decision tree early warning score based on routine laboratory test results for the discrimination of hospital mortality in emergency medical admissions. Resuscitation 2013, 84, 1494-1499. [CrossRef]

39. Udy, A.A.; Scheinkestel, C.; Pilcher, D.; Bailey, M. The Association Between Low Admission Peak Plasma Creatinine Concentration and In-Hospital Mortality in Patients Admitted to Intensive Care in Australia and New Zealand. Crit. Care Med. 2016, $44,73-82$. [CrossRef]

40. Cartin-Ceba, R.; Afessa, B.; Gajic, O. Low baseline serum creatinine concentration predicts mortality in critically ill patients independent of body mass index. Crit. Care Med. 2007, 35, 2420-2423. [CrossRef] [PubMed]

41. Brabrand, M.; Knudsen, T.; Hallas, J. Identifying admitted patients at risk of dying: A prospective observational validation of four biochemical scoring systems. BMJ Open 2013, 3, e002890. [CrossRef]

42. Kim, S.W.; Li, J.Y.; Hakendorf, P.; Teubner, D.J.; Ben-Tovim, D.I.; Thompson, C.H. Predicting admission of patients by their presentation to the emergency department. Emerg. Med. Australas. 2014, 26, 361-367. [CrossRef] [PubMed]

43. Mohammed, M.A.; Rudge, G.; Wood, G.; Smith, G.; Nangalia, V.; Prytherch, D.; Holder, R.; Briggs, J. Which is more useful in predicting hospital mortality-Dichotomised blood test results or actual test values? A retrospective study in two hospitals. PLoS ONE 2012, 7, e46860. [CrossRef] [PubMed] 